\title{
Analytical Separations of Mammalian Decomposition Products for Forensic Science: A Review
}

\author{
Swann, L.M. ${ }^{\mathrm{a}}$, Forbes, S.L. ${ }^{\mathrm{b}}$ and Lewis, S.W. ${ }^{\mathrm{a}}$ \\ ${ }^{a}$ Department of Chemistry, Curtin University of Technology, GPO Box U1987 Perth \\ Western Australia 6845 \\ ${ }^{b}$ Faculty of Science, University of Ontario Institute of Technology, Oshawa, Ontario,
} Canada, L1H $7 K 4$

*Author for correspondence: s.lewis@curtin.edu.au

\begin{abstract}
The study of mammalian soft tissue decomposition is an emerging area in forensic science, with a major focus of the research being the use of various chemical and biological methods to study the fate of human remains in the environment. Decomposition of mammalian soft tissue is a postmortem process that, depending on environmental conditions and physiological factors, will proceed until complete disintegration of the tissue. The major stages of decomposition involve complex reactions which result in the chemical breakdown of the body's main constituents; lipids, proteins, and carbohydrates. The first step to understanding this chemistry is identifying the compounds present in decomposition fluids and determining when they are produced. This paper provides an overview of decomposition chemistry and reviews recent advances in this area utilising analytical separation science.
\end{abstract}

Keywords: decomposition chemistry, analytical separations, forensic science 


\section{Table of Contents}

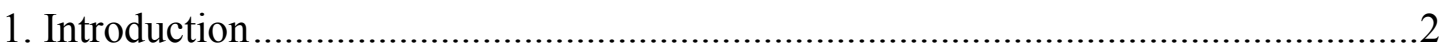

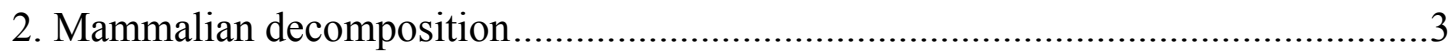

3. Non-chromatographic approaches to chemical studies of decomposition.................5

3.1 Chemical techniques for locating clandestine human remains .........................5

3.2 Chemical techniques for the identification of adipocere ................................

4. Chromatographic studies of decomposition products .............................................

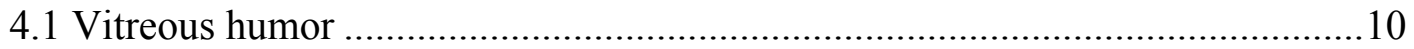

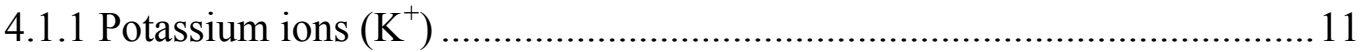

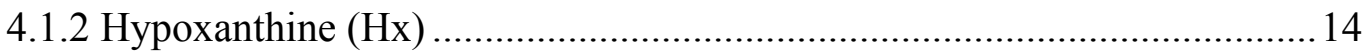

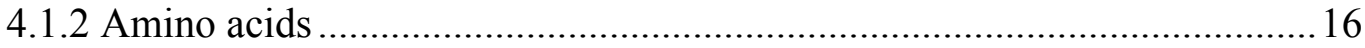

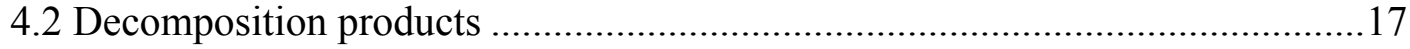

4.2.1 Decomposition fluid and soil solution analysis ...................................... 17

4.2.2 Volatile organic compounds (VOCs) …...............................................22

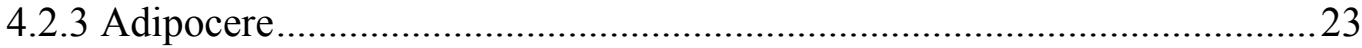

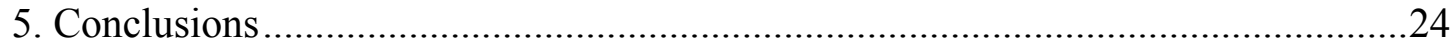

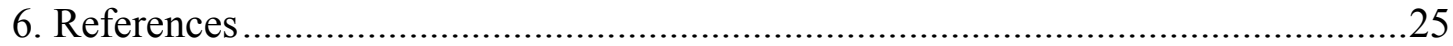

\section{Introduction}

The study of mammalian soft tissue decomposition is an emerging area in forensic science, with a major focus of the research being the use of various chemical and biological methods to study the fate of human remains in the environment. Such techniques have major roles to play in locating clandestine gravesites [1], assisting in the estimation of postburial interval [2].

Decomposition of mammalian soft tissue is a postmortem process that, depending on environmental conditions and physiological factors, will proceed until complete disintegration of the tissue [3]. An understanding of this process is extremely important for investigations of suspicious deaths as it complicates determination of cause of death and makes the estimation of postmortem interval very difficult. The major stages of decomposition involve complex reactions which result in the chemical 
breakdown of the body's main constituents; lipids, proteins, and carbohydrates [4]. As decomposition proceeds, these macromolecules degrade to their structural components which include amino acids, fatty acids, and glucose [5]. The precise details of the biochemical pathways involved, along with a detailed knowledge of the temporal and environmental variation that may be observed have yet to be examined in detail. It has also been suggested that temporal variation of certain chemical species could be used to age decomposing remains and potentially aid in the determination of postmortem interval.

The first step to understanding this chemistry is identifying the compounds present in decomposition fluids and determining when they are produced. However, decomposition fluid is a challenging sample to study, as it is a complex chemical mixture with associated insect life, microbial organisms and other debris. While methods using colourimetry or fourier-transform infrared spectrophotometry can provide useful trend information, more selective analytical techniques are required to provide the level of chemical knowledge needed to fully understand the fundamental chemistry of decomposition. Separation science techniques such as gas chromatography, liquid chromatography and capillary electrophoresis offer this level of specificity. This paper provides an overview of decomposition chemistry and reviews recent advances in this area utilising analytical separation science.

\section{Mammalian decomposition}

After death, many physicochemical processes take place within the corpse, with the resulting changes from these occurring in a predictable order. The rate of change is strongly influenced by environmental factors, the most significant being temperature [6-9]. The physical principle known as Van't Hoff's rule, or the rule of ten, states that the velocity of chemical reactions increases two or more times with each $10{ }^{\circ} \mathrm{C}$ rise in temperature [9]. All decomposing bodies will go through the same decomposition process, but it is the variability in temperature that will determine the length of each stage and the overall velocity of the process [9]. A deviation in the body's ambient temperature to warmer or cooler surroundings will affect cellular metabolism by affecting the enzyme catalysts that regulate reactions within the body [9]. Within a few hours of death, investigators may use the rate of cooling of the body, postmortem 
lividity, potassium levels in vitreous fluid, and rigor to estimate postmortem interval. However these methods can only be used shortly after death, and have limited accuracy $[6,7]$. Thus, once visible decomposition changes commence, the techniques available to the forensic scientist are greatly reduced.

Decomposition commences almost immediately after death [10], sometimes within the first 4 minutes $[5,11]$, depending on environmental conditions and surroundings. It can be characterised by two main stages, pre and post skeletonisation [12]. Preskeletonisation can be further broken down into four subsequent stages; fresh, bloated, decay and dry, as first described by Reed in 1958 [13]. A summary of the physical changes observed in each of these stages can be seen in Table 1.

The first identifiable process is autolysis, occurring during the fresh stage and literally meaning self-digestion of cells. Autolysis occurs first in the most metabolically active cells, i.e. cells where characteristically high rates of ATP production are more sensitive to anoxia [9]. It is thought to be triggered by the decrease in intracellular $\mathrm{pH}$ occurring as a result of the decreased oxygen levels after death [4]. The onset of autolysis can be observed by the presence of fluid filled blisters on the skin, and skin slippage $[5,11]$ as cellular membranes dissolve, releasing nutrient rich cellular fluids into the body [11]. Tissues containing cells with the highest rate of ATP synthesis and membrane transport should typically decompose first [9].

Following autolysis, the second process in decomposition is the bloated stage, where the beginnings of putrefaction are seen. This is the destruction of the soft tissues of the body by the action of microorganisms (bacteria, fungi and protozoa) in a mostly anaerobic environment. Putrefaction is identifiable by a green/purple discolouration of the skin and occurs usually between 36-72 hours after death $[5,9,10]$. The discolouration seen on the body is the result of variously coloured pigments released into the tissues of the abdomen by lysing pancreatic cells [9]. The result of putrefaction is the catabolism of carbohydrates, proteins and lipids present in soft tissues into gases, liquids and simple molecules $[5,9,11]$. The trapped volatile gases and fluid are responsible for the bloating of the carcass and a build up in pressure can result in purging from the body, often severe enough to cause additional postmortem injuries $[5,11]$. 
Following the purging of gases, the active decay stage begins. Additional volatile fatty acids are produced from the continued breakdown of muscle, and the decomposition of protein and fat producing phenolic compounds and glycerols [5, 11]. Decomposition products such as putrescine and cadaverine are also detectable in this stage and insect activity is at a premium [12]. Putrefaction is still occurring during active decay, as chemical constituents are still being degraded and released.

\section{Table 1: Overview of mammalian decomposition}

The dry stage is the final stage of the decomposition process. In this stage, any remaining moist skin and tissue is converted to a 'leathery-like' sheet that adheres to bone $[5,11]$. Skeletonisation is characterized by the appearance of exposed bone in over $50 \%$ of the body, but erosion of the skeletal elements has not yet begun [14]. This process will proceed until only the harder and more resistant bone, teeth and cartilage remain [10]. Chemical weathering of these remains continues but the time taken for this deterioration is considerably longer than previous stages of decomposition. Diagenesis, or the exchange of ionic species between bones and their surrounding environment, occurs, but at a rate dependent on the changing ratios of calcium and phosphate in a variety of soils [9].

Although decomposition is divided into these four stages, the distinction between the stages can be difficult to identify. Alternatively, stages may be absent altogether.

\section{Non-chromatographic approaches to chemical studies of decomposition}

\subsection{Chemical techniques for locating clandestine human remains}

A major area of investigation within the field is the application of physical and chemical techniques for locating clandestine human remains. In many instances, bodies are concealed by burial, which has a confounding effect on the search and location of the remains. Numerous techniques have been applied to forensic search 
and recovery situations including the use of cadaver dogs [15], botanical evidence associated with grave sites [16, 17], probing [18], thermal imaging [16], and the use of geophysical equipment such as the ground penetrating radar [19-21]. Each of these techniques has associated limitations and is best applied in a sequential manner for locating buried human remains [16].

Recently, chemical analysis of soils related to decomposition sites has been proposed as an alternative method for detecting clandestine graves [22-24]. The process of soft tissue decomposition results in a significant pulse of nutrients into the soil surrounding a cadaver. A proportion of these nutrients result from the release of nitrogen-containing compounds within the body, which include proteins, peptides, amino acids, and amines [10]. These nitrogenous compounds have the ability to react with ninhydrin, a chemical that is commonly available in police and forensic laboratories due to its use as a chemical enhancement technique for fingerprint visualisation [25]. In 2008, Carter et al. hypothesised that the decomposition of a body would result in an increase in ninhydrin reactive nitrogen (NRN) and may provide a new technique for identifying gravesoil (i.e. soil associated with a decomposing cadaver) $[22,26]$.

Their study involved the burial of juvenile rats (Rattus rattus) in three contrasting soil sites followed by sequential harvesting at pre-assigned postburial intervals (PBI). Gravesoil collected from beneath the decomposing cadavers was analysed using an NRN chemical protocol which involved the extraction of nitrogenous-compounds from the soil, reaction with ninhydrin reagent, and determination of the absorbance at $570 \mathrm{~nm}$ using spectrophotometry [27]. The concentration of NRN was determined by comparison with a leucine standard. The gravesoil samples demonstrated a 1.4-2.2fold increase in NRN when compared to the control samples. The authors suggested that the significant increase of NRN in soil following decomposition of a cadaver had the potential to be used as an investigative technique for locating clandestine gravesites [22].

An additional study applied the NRN technique proposed by Carter et al. [22] to an investigation of swine (Sus domesticus) carcass decomposition in both burial and surface decomposition scenarios [24]. The study involved the use of larger swine 
carcasses as analogues for human decomposition. Six carcasses were placed in shallow gravesites and a sequential destructive sampling regime was used to collect gravesoil samples at specific postburial intervals. This study expanded on the study conducted by Carter et al. [22] by investigating the lateral diffusion of NRN from the decomposition site. The authors hypothesised that NRN concentrations would increase as decomposition proceeded, but would decrease as the distance from the cadaver increased [24]. To study this hypothesis, gravesoil samples were collected from the centre and edge of each gravesite once a month for a period of six months, as well as from the base and walls of the graves at the time of exhumation. Additionally, five swine carcasses were placed on a soil surface and allowed to decompose for 97 days during which time soil samples were collected from beneath the decomposing carcasses. The ninhydrin analysis was adapted from Carter et al. [22] and the absorbance was scanned from 500-640 nm using a UV-Visible Spectrometer. The results indicated that NRN could detect gravesoil in the early postmortem period $(\sim 2$ months postburial) and that the lateral diffusion of nitrogen influx was narrow in a gravesite. In contrast, the NRN concentration was significantly higher during both the early and later postmortem stages for the carcasses decomposing on the surface. These results demonstrated the potential of the technique for detecting the original site of decomposition for cadavers that have been scavenged or subjected to postmortem relocation.

A case summary presented in 2009 details the application of the NRN technique to an outdoor death scene following disturbance of the remains, most likely through the activity of scavengers [23]. The colourimetric technique was used to assist with determining the location of death and the origin of decomposition. Soil samples were collected from several locations including the presumptive primary decomposition site (head and torso), the lower body, arm and hand, scalp, and control sites. The soil collected from the presumptive decomposition site demonstrated a significantly higher concentration of NRN than the other sites and it was concluded that decomposition had occurred in this location. The value of this method as a quantitative chemical alternative for locating decomposed human remains and decomposition sites was thus confirmed [23]. However, exactly what constitutes NRN in the context of these decomposition studies has yet to be established. 
A novel NRN technique using headspace collection has recently been proposed [28] and is based on a purge and trap method using a motorized pipetter and an activated, alumina-coated, porous layer open tubular (PLOT) column. The study utilized feeder rat carcasses placed on either the soil surface or buried within the soil, then sealed in pressed wooden boxes. Samples were collected by drawing the headspace through PLOT columns, which were pierced through septum ports placed on the compartment lids. The adsorbed compounds were eluted by forcing a $2 \mathrm{M} \mathrm{KCl}$ solution through the PLOT column and into a vial containing ninhydrin reagent. Following dilution with an ethanol solution, the absorbance of the sample was measured at $570 \mathrm{~nm}$ using a diode-array UV-Vis spectrophotometer. The method was successful at detecting NRN with only a $5 \mathrm{~min}$ headspace collection period. The average recovered masses of NRN were higher for both exposed and buried carcasses when compared to the blank (soil) samples. NRN was not detected during the first 4 weeks of decomposition but was detected in the headspace of the compartments in weeks $5,6,10$, and 20 . In contrast to the study by Van Belle et al [25], slightly higher masses of NRN were detected for the buried carcasses compared to the exposed carcasses. However, the experimental setup differed considerably between both studies (i.e. one was in a natural environment and the other was in a controlled environment) and this result may not be representative of all forensic scenarios. The study was useful in proposing an alternative use of the NRN technique for locating clandestine graves.

\subsection{Chemical techniques for the identification of adipocere}

Adipocere, a postmortem decomposition product that forms from the neutral fats present in soft tissue, may be found directly on decomposed remains or in the surrounding soil environment, especially in burials. Spectroscopic techniques have also been applied to forensic decomposition studies to identify fatty acid concentrations indicative of adipocere formation. The use of infrared spectroscopy as a qualitative tool for determining the lipid profile of soft tissue has been well documented [29-31]. In 2000, Stuart et al. [30] proposed a diffuse reflectance infrared Fourier transform (DRIFT) spectroscopy technique to study soil samples believed to contain adipocere from human remains. The technique involved minimal sample preparation and was useful in demonstrating the degradation of triglycerides into fatty acids. Carbonyl bands in the $1740-1700 \mathrm{~cm}^{-1}$ region were identified as being 
characteristic of adipocere formation and assisted in determining the degree of formation that had occurred. DRIFT spectroscopy was shown to be a rapid and effective method for detecting and characterising adipocere formation in soils [30]. The same technique was also successfully applied to adipocere samples formed in aqueous environments [31]. The chemical composition of pig and human adipose tissue degradation was investigated over a period of 21 days. The lipid profile for both pig and human tissue demonstrated a decrease in carbonyl bands relating to triglycerides and a concomitant increase in bands relating to free fatty acids as immersion time increased. The formation of fatty acids in the human tissue samples appeared to occur more rapidly than in the pig tissue samples.

An alternative Fourier transform infrared (FTIR) spectroscopy method has been applied to the investigation of adipocere formed in soils and mock coffins [29]. Attenuated total reflectance (ATR) infrared spectroscopy is a surface analytical technique that requires little to no sample preparation [32]. Samples can be extracted using a solvent and cast as a film on a slide, then placed directly onto the ATR crystal. This method also proved to be effective in characterising the formation of adipocere in soils based on changes in the carbonyl region of the spectrum. Analysis by ATR spectroscopy was also valuable in demonstrating the affect of the burial environment on the rate of adipocere formation.

\section{Chromatographic studies of decomposition products}

While the non-chromatographic approaches described above have been valuable in providing a qualitative profile of the decomposition fluid as it is formed and released into the surrounding environment, further information is required regarding the biochemical pathways involved in the process. For this reason, separation methods are being investigated with the goal of providing quantitative data that will assist in strengthening the knowledge base relating to decomposition chemistry as is applies to geoforensics.

Initial studies into the use of chromatographic methods for the analysis of decomposition products were very much based on the principle of identifying chemical markers that could be used to give an estimation of postmortem interval. 
The use of a chemical biomarker would aid in the elimination of examiner bias as well as providing an orthogonal method that would aid in offering a more reliable estimate of postmortem interval than existing techniques on their own. The earliest reports of this approach were made in the 1960's, focusing on the measurement of potassium ion $\left(\mathrm{K}^{+}\right)$concentration in vitreous humor by flame photometry [33, 34], Whilst several studies have continued this work, there has been a shift away from the use of these early techniques towards separation science, which are less prone to matrix interferences [35]. Initial studies made use of gas chromatography, but more recently, liquid chromatography and capillary electrophoresis have been applied in an attempt to utilise the temporal variation of the chemical markers of decomposition in order to estimate postmortem interval [5, 12, 36-39]. A summary of chromatographic techniques applied to various decomposition matrices is shown in Table 2, and discussed below.

Table 2. Summary of chromatographic methods used in the analysis of decomposition products and to aid in the estimation of postmortem interval.

\subsection{Vitreous humor}

In the early stages of postmortem interval, one of the most widely reported biochemical methods to estimate postmortem interval is the determination of potassium ion $\left(\mathrm{K}^{+}\right)$and hypoxanthine $(\mathrm{Hx})$ concentrations in vitreous humor $[33,34$, $41,57,58]$. The vitreous humor refers to the fluid that fills the vitreous body (or posterior chamber) of the eye [44]. Its potential usefulness for postmortem chemical analysis results from it being anatomically confined [45] and thus somewhat 'protected' and preserved for longer time periods from bacterial contamination, enzymatic activity and putrefactive changes [34, 43]. It has also been stated that vitreous humor has advantages for chemical analysis for biomarkers compared to the use of blood and cerebrospinal fluid (CSF) due to accessibility [34], ease of sampling [43], less susceptibility than blood to rapid chemical changes [58] and relative independence from environmental influences [59]. 
The following section discusses the most prominent analytes, potassium ions and hypoxanthine, which have been analysed in vitreous humor in an attempt to estimate postmortem interval. To date, no reliable method for postmortem interval estimation based on measurement of either Hx or potassium ions has been developed. There has been significant disagreement on how $\mathrm{Hx}$ and potassium ion concentrations vary in vitreous humor, and there is a wide variability in measurements taken between samples $[34,41,43,57,58,60,61]$. This unreliability limits the use of individual measurements of both potassium ions and $\mathrm{Hx}$ as indicators of postmortem interval. Various statistical approaches have been applied in an attempt to improve the accuracy in estimation. Typically, the postmortem interval has been used as the independent variable and the potassium ion concentration as the dependent variable in linear regression analysis. Recently, it has been suggested that using potassium ion concentration as the independent variable will improve the postmortem estimation [47, 62]. This has also been the suggestion for the use of $\mathrm{Hx}$ in determining postmortem interval. However, a review in 2006 found that in a random sample of 492 cases, only 153 were within the predicted postmortem interval with the remaining 339 having a systematic overestimation [62]. Several authors have suggested that a combination of both $\mathrm{Hx}$ and potassium ion determination would be more effective in estimating postmortem interval than either individual measurement [41, 43]. However, problems arise for two reasons. From an analytical perspective, method development needs to be established specifically for the vitreous humor matrix and not based on other matrices such as serum or urine [63] and consistent analytical protocols need to be employed to ensure reliable, reproducible results between samples and between laboratories. From a forensic viewpoint, each determination of postmortem interval needs to take into account several factors including cause of death [47], environmental conditions [61, 64, 65], body temperature [64], age of deceased [64], duration of terminal episode [61, 64], chronic illness [34, 57, 61] and alcohol consumption [65]. The combination of all of these factors makes biochemical indicators in vitreous humor a potential complementary technique rather than a standalone method for postmortem interval estimation.

\subsubsection{Potassium ions $\left(K^{+}\right)$}


A correlation between concentration of potassium ions and postmortem interval was first reported by Jaffe in 1962 [33]. This study showed an increase in potassium concentration in 36 determinations up to 125 hours postmortem [33]. Several studies regarding the usefulness of this as a biochemical indicator of postmortem interval have since been reported [34, 57-60].

Potassium was chosen as an analyte over other components present in vitreous humor for a variety of reasons. Instrumentation at the time of this work (1960's) was not sensitive enough to detect very low levels of some constituents, such as the levels of total proteins and albumins [58]. Other components such as alkaline phosphotase were uniformly negative with respect to concentration and associated error. Of the electrolytes analysed (sodium, chloride and potassium), sodium and chloride remained stable for long periods of time after death [34, 58], discounting them as indicators of postmortem interval. Vitreous potassium was the only analyte that showed an increase in concentration after death, which allowed it to be expressed by a linear mathematical function [58].

While early work focused on methods using flame photometry $[33,57,58,60]$ and ion selective electrodes (ISE) $[65,66]$, it is well documented that several discrepancies exist between studies in the estimation of postmortem interval using vitreous potassium ion concentrations [61, 64, 65]. Several papers report linear equations for the determination of postmortem interval [34, 41, 43, 57, 58, 60, 61], however, the intercept varies markedly, thereby, altering the estimation of postmortem interval. These studies also have a wide range of associated uncertainty, ranging from \pm 4.7 hours [34] to \pm 34 hours [61]. Suggested reasons for these discrepancies include ambient temperature [61, 64], elevated urea levels [65], alcohol consumption [65], sample acquisition and storage [45] and analytical instrumentation $[45,64]$. Such variation limits the use of vitreous potassium ion concentration as a reliable indicator of postmortem interval.

The first reported shift away from flame photometry for the analysis of potassium ions in vitreous humor to determine postmortem interval was published by Ferslew et al. in 1998 [44]. Ferslew compared capillary electrophoresis (CE) [44], with UV detection at $214 \mathrm{~nm}$, with an ion selective electrode (ISE) method for the 
determination of vitreous potassium in 25 human subjects. CE is useful at handling samples that are particularly complex or 'dirty' in nature [67-69] as can often be the case with work involving decomposition samples. The use of CE allowed for rapid analysis time ( $<5$ mins), improved separation, more symmetrical peak shapes, enhanced detection limits and direct analysis of the specimen [44], whilst only requiring very small sample volume [35]. Although analysis time was relatively quick, the detection limits achieved were mmol/L, which is comparable with both flame photometry and ISE methods. The data analysis reports a significant linear correlation $\left(\mathrm{r}^{2}=0.9642\right)$ between potassium ion concentrations obtained by both $\mathrm{CE}$ and ISE methods.

The disadvantage of the CE method was the requirement of a complex buffer system for analysis, involving reagents capable of chemical complex formation, 4methylbenzylamine, 18-crown-6-ether and d,1-alpha-hydroxybutyric acid (HIBA) [44]. Addition of the 18-crown-6-ether was used to prevent co-migration of the potassium and ammonia peaks [35, 44, 45]. Complete separation was essential to provide the possibility of accurate quantitation of potassium concentrations. HIBA was used in the run electrolyte as a chelating agent to control the flow of buffer through the capillary in order to improve peak resolution and shape [44]. The addition of HIBA was reported as affecting the complete resolution of all the cations studied [45]. UV-absorbing additives, such as 4-ethylbenzylamine and imidazole, were added as their electrophoretic mobilities match that of the analytes. They were therefore suitable for detection of ammonium, alkali earth and transition metal cations by $\mathrm{CE}$ $[44,45]$.

This complex buffer system has been used in several reported CE studies [35, 45, 46]. A comparison between CE-UV-Vis and flame photometry for samples with a known postmortem interval of 5-96 hours, resulted in a correlation coefficient of 0.9333 for the potassium ion concentrations in 12 real samples [45]. This work reports detection limits down to $\mu \mathrm{mol} / \mathrm{L}$ (based on $\mathrm{S} / \mathrm{N}$ of 3), 1000 times better than flame photometry [45]. A significant linear correlation $\left(r^{2}=0.904\right)$ has also been reported between potassium ion concentration and postmortem interval using the CE-UV-Vis method for 20 subjects who were deemed to have died a violent death, however no information was given in regards to uncertainty in the estimation [45]. Using the same 
CE method, a similar correlation was reported in later work by the same authors, comparing potassium ion concentrations from both eyes [35]. Postmortem interval for these samples ranged from 7-144 hours. Although the determination of potassium ion concentrations gave similar results, the reliability and improved accuracy of CE, as well as the need for small sample volumes, make it advantageous for the determination of vitreous potassium over non-separative methods [45].

An attempt to improve the statistical correlation between vitreous potassium and postmortem interval using $\mathrm{CE}$ with indirect UV detection was achieved by utilising a chemometric approach [46]. Using the complex buffer system described in previous reported studies and applying artificial neural networks, the authors reported a good linear correlation $\left(\mathrm{r}^{2}=0.98\right)$ in comparison to the traditional linear least squared (LLS) method, improving the prediction of postmortem interval by a factor of 5 [46]. The advantage of a chemometric approach is the decrease in the number of required experiments, a decrease in analysis time once the method had been optimised, plus an enhanced potential for statistical evaluation of any data [46].

In 2007 , low pressure ion chromatography with conductivity detection was used for the determination of vitreous potassium concentration as an alternative to CE, with applications to postmortem interval [52]. The study involved 62 samples from autopsy cases with known postmortem interval ranging from 1-27 hours achieving a detection limit of $1 \mathrm{mmol} / \mathrm{L}$ and limit of quantitation of $2 \mathrm{mmol} / \mathrm{L}$. The advantage of this method is the simplicity of the solvent system and sample preparation making it more cost effective than CE [52].

\subsubsection{Hypoxanthine $(H x)$}

Hypoxanthine (Hx) is a degradation product of adenosine [42] and is elevated due to hypoxia prior to death [41]. Hypoxanthine has previously been analysed by High Performance Liquid Chromatography (HPLC) with applications generally in the pharmaceutical and medical fields [70]. The potential for the use of vitreous $\mathrm{Hx}$ as a postmortem interval indicator was first described by Rognum et al. in 1991 [41]. HPLC with UV detection was successful in demonstrating a linear relationship between $\mathrm{Hx}$ and postmortem interval $(\mathrm{r}=0.93)$ in 87 subjects with a known 
postmortem interval of less than 120 hours [41]. Controlled conditions were employed to study the effect of four different storage temperatures on the estimation of postmortem time. Using HPLC methods that were previously described in the literature, an improvement in the detection limit was obtained. The greater sensitivity of HPLC demonstrates its ability to determine analytes over a greater time span than previously used flame photometry and ISE. Rognum also concluded that the uncertainty associated with the analysis of Hx by HPLC showed a smaller range of scatter when compared with the determination of potassium by flame photometry for the same samples, particularly in the first 24 hours. The gradient for the determination of $\mathrm{Hx}$ becomes steeper with increasing ambient temperature [41]. This is in accordance with the reported literature, which states that temperature is the factor with the greatest impact on rate of decomposition and subsequently, the determination of postmortem interval $[8,12,14]$.

In 1994, Madea et al. published results that contradicted previous literature reports of the linear relationship between $\mathrm{Hx}$ and postmortem interval [42]. Vitreous Hx was analysed by HPLC, using a method based on the work of Rognum, but concluded that the smaller margin of error was associated with the determination of potassium ions by ion selective electrodes rather than the HPLC analysis of Hx. It should be noted that Rognum determined potassium ion concentrations using flame photometry. Also, potassium ions and $\mathrm{Hx}$ were shown to rise linearly immediately postmortem and not after 24 hours as had been reported [41]. Since both studies used similar analytical methods, this discrepancy is accounted for by the authors as a difference in sample collection itself, and the duration of hypoxia prior to death [42]. In 1997 [43], an effort was made to compare the linear equations provided by the 3 separate studies of Madea [42], Sturner [34] and Rognum [41]. HPLC with UV detection was used to determine Hx whilst flame photometry was used to measure vitreous potassium ion concentration [43]. It was concluded that there was a linear correlation between both $\mathrm{Hx}$ and potassium ion concentration with postmortem interval. However, the experimental method used, sampling techniques and the make-up of the sample group itself were the reasons behind the observed differences in the resulting linear equations used to estimate postmortem interval [43]. The result of this work combined results from both $\mathrm{Hx}$ and vitreous potassium measurements to arrive at a new equation that claimed improved accuracy for postmortem interval determination. This 
was achieved by taking the mean of the individual estimates of postmortem interval given by the two separate equations, reducing the standard deviation of the overall estimate [43].

In 2002, the estimation of postmortem interval was improved using the hypothesis that cause of death is a factor in the level of $\mathrm{Hx}$ in the vitreous humor [47]. The analysis determined Hx using HPLC and only investigated cases where the cause of death was the same (death by hanging). Using 206 samples from 176 subjects with a known postmortem interval ranging from 1.08 - 28.91 hours, detection limits in $\mu \mathrm{mol} / \mathrm{L}$ range were obtained (exact numbers not given). The linear correlation between postmortem interval and both potassium ions $\left(\mathrm{r}^{2}=0.818\right)$ and $\mathrm{Hx}\left(\mathrm{r}^{2}=0.757\right)$ was reported by using an inverse prediction statistical method. The inverse prediction method was again used for the determination of $\mathrm{Hx}$ in vitreous humor from 134 samples [51]. A revised HPLC method showed a decrease in analysis time and improved reliability [51]. Although no information is given in regards to the separation conditions in the 2002 paper, in 2006, Munoz et al. state that the sample preparation is significantly faster and detection limits are improved down to 0.02 $\mu \mathrm{mol} / \mathrm{L}$ for $\mathrm{Hx}$.

More recently Passos et al. moved away from a chromatographic approach for the determination of $\mathrm{Hx}$ and instead used a sequential injection analysis (SIA) system that enabled the simultaneous determination of both potassium and Hx in vitreous humor [71]. SIA is an automated flow based technique that allows multianalyte determinations within a single instrument [72]. Detection limits of $1.02 \mu \mathrm{mol} / \mathrm{L}$ for $\mathrm{Hx}$ and $5 \times 10^{-5} \mathrm{mmol} / \mathrm{L}$ for potassium ions were achieved respectively. The Hx levels showed a greater linear correlation to postmortem interval $\left(r^{2}=0.998\right)$ than potassium ions, which was in agreement with some of the earlier literature reports [41, 43]. While this approach shows great promise for multianalyte determinations of this kind, SIA instrumentation is not widely available and requires customising for specific applications [72].

\subsubsection{Amino acids}


Vitreous humor has also been analysed for free amino acids. Erdei and Vass used paper chromatography to identify 13 amino acids, but this early research did not attempt to correlate concentrations with postmortem interval [73]. Prior to this, most amino acid analysis had been performed using non-separative methods such as amino acid nitrogen analysis [74-76]. Very few publications deal with the amino acid content in vitreous humor, particularly in relation to postmortem interval. The work done in 1988 by Patrick and Logan [40] was the first report of a chromatographic separation showing a relationship between postmortem interval and free amino acid concentration in vitreous humor [40]. Analysis was by cation exchange chromatography using a Technicon TSM amino acid analyser. This work was completed on 120 cases of infants less than 1 year old, with samples having a postmortem interval up to 96 hours. 27 amino acids showed a logarithmic linear relationship with postmortem interval although at different rates. The conclusion of this work was that samples showed a reliable result for the estimation of postmortem interval but only if they were collected within the first 24 hours.

In 2008, HPLC was used to determine free amino acids in both vitreous humor and cerebrospinal fluid [54]. This work used an o-phthalaldehyde (OPA) derivatisation procedure prior to analysis for 58 samples with an average postmortem interval of 23.9 hours (range 5-60 hours). No information is given in regards to detection limit, analysis time or error in estimation of postmortem interval. While the authors claim a linear relationship between selected amino acid concentrations in vitreous humor and postmortem interval, the correlation co-efficients presented $(0.3191 \leq \mathrm{r} \leq 0.4508)$, would not support this contention to any great extent.

\subsection{Decomposition products}

\subsubsection{Decomposition fluid and soil solution analysis}

A method with application to both early and late stages of decomposition would be invaluable to forensic investigators in cases of suspicious deaths. In the later stages of decomposition, forensic entomology has been found to be a useful tool in the estimation of postmortem interval. Forensic entomology involves the recognition of arthropods (mostly insects), coupled with their sequential arrival times on a corpse 
and the developmental timetables of their offspring, to estimate the time and sometimes cause of death [77]. This technique has been extensively studied and used with a certain amount of success $[13,77-80]$. There are, however, situations in which the corpse has reached complete skeletonisation, or factors have affected the decay process (such as burial or low temperatures, insect access and presence of drugs [8184]). In such an event, the estimation of postmortem interval via entomology becomes difficult, if not impossible [85].

When considering the following body of work, it should be noted that due to the ethical issues involved in the use of human cadavers, pig (Sus dometica) carcasses are often used to model the human decomposition process $[85,86]$. They are considered to be an acceptable substitute due to their similarity to human torsos in weight, fat to muscle ratio, hair coverage, biochemistry and physiology $[10,16]$.

Small organic molecules, such as short chain volatile fatty acids $\left(\mathrm{C}_{2}-\mathrm{C}_{5}\right)$, were the primary focus of early studies into the chemistry of decomposition in the mid-late postmortem interval. Work by Vass et al. $[5,12]$ used soil solution analysis (the liquid phase between particles) to analyse five microbially produced volatile fatty acids (VFAs); propionic, butyric, iso-butyric, valeric and iso-valeric acid, and their variation over time, with regards to accumulated temperature (Figure 1). An advantage of using VFAs is that they can remain detectable for a considerable amount of time [39], thus extending their use potentially into the late postmortem interval. An early application of this approach was by Tuller, who determined VFAs in samples collected from known execution and gravesites in the former Yugoslavia [39].

\section{Figure 1: Structures of short chain Volatile Fatty Acids (VFAs).}

The analysis of VFAs has typically been carried out using Gas Chromatography (GC). GC provides a rapid and reliable method [87-90] for the analytical separation and subsequent analysis of volatile and thermally stable mixtures, showing good sensitivity and reproducibility. Early studies attempted to deal with peak tailing and ghosting as well as finding the most effective column for separation [89, 91]. 
Vass identified and quantified 5 VFAs from human cadavers using a relatively simple aqueous dilution and filtration method to prepare samples for analysis [12]. Each sample was then acidified prior to being analysed using packed column GC with flame ionisation detection (FID). The addition of formic acid increased reproducibility by minimising peak tailing and ghosting and improved the analyte volatility $[87,91]$. Vass also stated that VFAs became more volatile at $\mathrm{pH}<7.0$ [12]. Vass used accumulated-degree-days (ADD) to show specific ratios in concentrations of propionic, butyric and valeric acids during decomposition. The estimate given by this method in determining postmortem interval is currently \pm 2 days [5].

In more recent studies decomposition fluids in the absence of a soil matrix were investigated, using pig carcasses in place of human cadavers. Samples were analysed using capillary GC with mass spectrometric (MS) detection [36]. Capillary GC has several advantages over packed column GC including the ability to produce faster and more efficient separations with a higher degree of resolution as well as greater sensitivity and greater chemical inertness to the analyte [92-94]. In contrast to the sample preparation published [12], formic acid was eliminated from the procedure when it was shown to have no significant effect on the volatility or reproducibility of standards run in triplicate [36]. This meant that sample preparation was now a simple aqueous dilution and filtration prior to analysis.

An increase in the column temperature and the use of GC-MS also allowed the identification of several previously unreported compounds present in decomposition fluid that were eluting late in the analysis time (Figure 2). The main compounds identified were long chain acids, as well as phenylacetic acid, phenylpropionic acid, 2-piperidone and iso-caproic acid, which were of potential forensic significance. In contrast to previous findings, the authors found no patterns in the VFAs with ADD, however, the presence of long chain fatty acids (unreported using Vass's GC-FID method) showed cyclic trends that were tentatively related to the fly life cycle [37].

Figure 2: Chromatogram showing compounds produced during a pork rasher trial with identified peaks: acetic acid (1), propionic acid (2), trimethylacetic acid 
(TMA) (3), butyric acid (4), iso-valeric acid (5), 2-piperidone (6), phenylacetic acid (7), phenylpropionic acid (8), myristic acid (9), palmitic acid (10), palmitoleic acid (11), stearic acid (12), oleic acid (13), linoleic acid (14) [36].

Vass and coworkers in 2002 used GC-MS to analyse amino acids, neurotransmitters and decomposition by-products (cadaverine and putrescine) as a new method for determining postmortem interval [5], revealing patterns useful for postmortem interval estimation of up to 3 weeks. The sample preparation involved two separate derivatisation procedures, one for the amino acids and one for the cadaverine and putrescine, as well as two separate temperature programs on the instrument. The samples were derivatised in order to increase their volatility, thermal stability and mass-spectral detection [5], however, the need for two derivatisation procedures significantly increased the sample preparation time and the potential for loss of analyte. Subsequent analysis of the data showed that neither putrescine nor cadaverine were useful indicators of postmortem interval and were disregarded from further work. Of the compounds analysed, Vass found that ratios between oxalic acid, gamma amino butyric acid (GABA), proline and methionine, phenylalanine, tyrosine, isoleucine and histidine showed linear relationships with postmortem interval [5], however, these results have not been replicated. Of these, oxalic acid was seen to be the most valuable indicator and its abundance was determined as a combination of both oxalic and glycolic acids, as these co-eluted during the analysis. The different acids were identified by their respective molecular ions; $\mathrm{m} / \mathrm{z}=261$ (oxalic acid) and $\mathrm{m} / \mathrm{z}=247$ (glycolic acid).

While the main focus of the above studies has been the estimation of postmortem interval, chemical analysis can also be used to establish the origin of identified compounds. This information can then be related back to the original composition of the carcass, as a large proportion of the decomposition products produced should reflect the fat and protein content of the remains. Methods of production for the compounds in decomposition fluid remain largely unproven, with most suggested pathways being based on previous microbial fermentation studies [95, 96]. For example, we detected phenylacetic acid and phenylpropionic acid have been detected in decomposition fluid [36]. According to previous studies of microbial fermentation, 
the amino acid phenylalanine, on putrefaction, yields 3 different aromatic acids; phenylacetic acid (produced by oxidation), phenylpropionic acid (reduction) and benzoic acid [89] (Figure 3).

\section{Figure 3: Degradation pathway of phenylalanine to produce phenylacetic and phenylpropionic acids.}

Phenylacetic and phenylpropionic acids are also produced by the deamination of tyrosine by anaerobic bacteria [97]. Subsequently, the presence of phenylalanine and tyrosine were determined in decomposition fluids using CE (see below).

Similar biosynthetic pathways were also proposed for other components identified in decomposition fluid [36]. This approach provides a framework for targeted analysis of decomposition products, thus allowing a clearer understanding of the chemistry of decomposition.

The limitations associated with the use of GC resulted in the development of new analytical methods to deal with the variety of compounds present in decomposition fluid. The 'dirty' nature of the sample, lends itself to frequent instrument maintenance, thus slowing down sample throughput [98]. Also, GC is unable to detect both long chain and short chain acids (both shown to be present in a sample of decomposition fluid) in a quantitative manner due to the polarity difference in the molecules [94, 98]. Detection of these compounds requires either derivatisation of samples, or the use of more complex methods, such as tandem GC to deal with this problem [94], thereby significantly increasing sample preparation times. In addition to this, analysis by GC requires that compounds are both volatile and thermally stable [32].

In an effort to further characterise non-volatile chemical compounds in decomposition fluid, an analytical method using CE with UV-Vis detection has been developed [38]. $\mathrm{CE}$ has been applied to the detection of nitrogenous compounds in a wide variety of matrices, particularly for forensic analysis $[99,100]$. CE offers the potential for highly 
efficient and rapid separations and thus is extremely useful when analysing complex mixtures. CE can cope with analytes not suitable for GC due to thermal instability, while providing more rapid separations than are achievable with LC, whilst still maintaining high resolution [101].

The simple CE method determined five amines (tryptamine, tyramine, benzylamine, aniline, indole) and three amino acids (tryptophan, phenylalanine, tyrosine) (Figure 4) in decomposition fluid [38].

Figure 4: Structures of amino acids and biogenic amines.

In order to improve resolution and total analysis time, the method was subjected to optimisation utilising a chemometric approach. A screening design was carried out followed by a central composite design, using peak resolution and total analysis time as response factors. The method was applied to the analysis of samples from a decomposition field trial to investigate the temporal variation of these compounds. A sample electropherogram from the field trial can be seen in Figure 5.

Figure 5: Electropherogram at optimised running condition showing compounds produced for a decomposition fluid sample with identified peaks: tryptamine (1), tyramine (2), neutral (3), tryptophan (4), tyrosine (5), phenylalanine (6) and unidentified components $(*)[38]$.

\subsubsection{Volatile organic compounds (VOCs)}

Volatile organic compounds (VOCs) associated with decomposition have long been used as a means of training cadaver dogs to aid in the detection of clandestine graves $[15,49,102,103]$. The most abundant compounds reported from several studies [15, $49,50,53,56]$ can be seen in Figure 6. A decomposition odor analysis database was established in 2004 to identify VOCs produced during the decomposition process 
[49]. This work used thermal desorption-gas chromatography-mass spectrometry (TD/GC-MS) to identify 424 compounds (and several more unidentified) that evolved from the cadavers with either no external signs of decomposition or in the very early stages. These compounds were then grouped into classes for ease of data analysis. These classes include cyclic and non-cyclic hydrocarbons, nitrogen and oxygen containing compounds, acids/esters, halogens, sulfur compounds, and other/miscellaneous compounds [49].

Figure 6: Structures of volatile organic compounds (VOCs).

VOCs evolved from a decaying body were analysed by TD/GC-MS to provide a chemical profile of decomposition $[50,53]$. Both of these studies yielded a chemical profile of decomposition but with significantly less compounds (30 [53] and 80 [50]) than previous work [49]. This is possibly due to sampling only taking place over a 24 hour period for cadavers with a known postmortem interval of 4 days [53] and 3-4 weeks [50] compared with 1.5 years [49] as well as preliminary data from a 12-yearold gravesite [49]. Recent work in this area showed 35 core compounds from 5 main classes evolved from the decaying body, with analysis again by TD/GC-MS [56]. The results of this work showed that the volatile pattern changes over time, which is in accordance with the reported literature [49].

\subsubsection{Adipocere}

Whilst not directly related to the estimation of postmortem interval, one of the most widely studied decomposition products is adipocere (see section 3.2). While FTIR analysis has been useful in studying trends, analysis of adipocere using GC-MS has allowed a more detailed understanding of its composition [97, 104] through rapid and simple methods with good reproducibility [55]. The major components identified were long chain fatty acids particularly myristic $\left(\mathrm{C}_{14: 0}\right)$, palmitic $\left(\mathrm{C}_{16: 0}\right)$ and stearic $\left(\mathrm{C}_{18: 0}\right)$, which are present in characteristic ratios $[55,97,104]$ (Figure 7). 


\section{Figure 7: Structures of long chain fatty acids.}

There are reports in the literature of trace levels of 10-hydroxystearic acid [104] and other unsaturated fatty acids, including linoleic $\left(\mathrm{C}_{18: 2}\right)$ [55], palmitoleic $\left(\mathrm{C}_{16: 1}\right)$ and oleic $\left(\mathrm{C}_{18: 1}\right)$ acids. The disadvantage of the analysis of adipocere is the requirement for sample pre-treatment, which is necessary to achieve a reliable and accurate quantitative determination by GC-MS [31, 55]. Methods such as thin layer chromatography and column chromatography $[105,106]$ have been utilised to separate adipocere from interfering compounds, however, these methods are often affected by low recoveries of lipids, large solvent requirements and oxidation of unsaturated fatty acids due to long term exposure to the ambient environment [31, $55]$.

\section{Conclusions}

A greater knowledge of decomposition chemistry will provide the necessary tools to assist in the detection of clandestine gravesites and the estimation of postmortem intervals in retrieved human remains. Advances in analytical separations have opened new avenues in the study of mammalian soft tissue decomposition. Analytical separations have enabled a more detailed picture of the decomposition process to be constructed. Further work in this direction will allow the construction of the various biosynthetic pathways that occur during decomposition. A surprising omission in the analytical separation techniques applied to studies of the products of mammalian decomposition is liquid chromatography-mass spectrometry (LC-MS), and it would be expected that this technique would be particularly useful for this application. We are currently carrying investigations in this area and our initial results will be published in due course.

There is a real need to develop viable alternatives to entomology for the estimation of postmortem intervals. While studies using analytical separations show promise for the estimation of postmortem interval through measurement of specific chemical species, these to date have yet to be fully validated. In all likelihood a single chemical test will 
not be accurate enough to determine postmortem interval [64]. If the potential for chemical methods to determine postmortem interval is to be realised, there is a need to develop harmonised analytical protocols through properly constituted collaborative trials. It will also be necessary to examine the potential differences between human and animal models, as the ability to use human subjects on a large scale is not going to be possible. It would be for seen that analytical chemistry, and particularly separation science will be essential for these studies to progress.

\section{Acknowledgments}

The authors wish to thank Dr Kathryn Linge (Department of Chemistry, Curtin University of Technology) for useful comments on the draft manuscript. Lisa Swann is supported by an Australian Postgraduate Award.

\section{References}

1. D.L. France, T.J. Griffin, J.G. Swanburg, J.W. Lindermann, G.C. Davenport, V. Trammell, C.T. Travis, B. Kondratieff, A. Nelson, K. Castellano, D. Hopkins, and T. Adair, in W.D. Haglund and M.H. Sorgs (Eds.), NecroSearch Revisited: Further multidisciplinary approaches to the detection of clandestine graves. CRC Press: Boca Raton, FL., 1997, pp. 497-509.

2. A. Ruffell and J. McKinley, Earth Sci Rev. 69(3-4) (2005) 235-47.

3. W.E.D. Evans, The Chemistry of Death, Charles C Thomas, Springfield, IL, 1963.

4. M.A. Clark, M.B. Worrell and J.E. Pless, in W.D. Haglund and M.H. Sorgs (Eds.), Postmortem changes in soft tissues. CRC Press: Boca Raton, FL, 1997, pp. 151-64.

5. A.A. Vass, S.A. Barshick, G. Sega, J. Caton, J.T. Skeen, J.C. Love, and J.A. Synstelien, J Forensic Sci. 47(3) (2002) 542-53.

6. B. Knight, Simpson's Forensic Medicine, 11 ed., Hodder Arnold Publications, New York, 1997.

7. R. Van den Oever, Med Sci Law. 16 (1976) 269-76.

8. R.W. Mann, W.M. Bass and L. Meadows, J Forensic Sci. 35(1) (1990) 10311 .

9. H. Gill-King, in W.D. Haglund and M.H. Sorgs (Eds.), Chemical and Ultrastructural Aspects of Decomposition. CRC Press: Boca Raton, FL., 1997, pp. 93-108.

10. B.B. Dent, S.L. Forbes and B.H. Stuart, Environ Geol. 45(4) (2004) 576-85.

11. A.A. Vass, Microbiol Today. 28 (2001) 190-92.

12. A.A. Vass, W.M. Bass, J.D. Wolt, J.E. Foss and J.T. Ammons, J Forensic Sci. 37(5) (1992) 1236-53.

13. H.B. Reed, Am Mid Nat. 59(1) (1958) 213-45.

14. A. Galloway, W.H. Birkby, A.M. Jones, T.E. Henry and B.O. Parks, J Forensic Sci. 34(3) (1989) 607-16. 
15. E.M. Hoffman, A.M. Curran, N. Dulgerian, R.A. Stockham and B.A. Eckenrode, Forensic Sci Int. 186(1-3) (2009) 6-13.

16. D.L. France, T.J. Griffin, J.G. Swanburg, J.W. Lindermann, G.C. Davenport and V. Trammell, J Forensic Sci. 37 (1992) 1445-58.

17. C.W. Watson and S.L. Forbes, J Can Soc Forensic Sci. 41 (2008) 199-207.

18. A. Ruffell, Forensic Sci Int. 151(2-3) (2005) 207-11.

19. J.J. Schultz, J Forensic Sci. 53(2) (2008) 279-87.

20. J.J. Schultz, M.E. Collins and A.B. Falsetti, Journal of Forensic Sciences. 51(3) (2006) 607-16.Doi 10.1111/J.1556-4029.2006.00129.X.

21. J.K. Pringle, J. Jervis, J.P. Cassella and N.J. Cassidy, J Forensic Sci. 53(6) (2008) 1405-16.

22. D.O. Carter, D. Yellowlees and M. Tibbett, J Forensic Sci. 53(2) (2008) 397400.

23. D.O. Carter, J. Filippi, L.G. Higley, T.E. Huntington, M.I. Okoye, M. Scriven, and J. Bliemeister, J Forensic Iden. 59 (2009) 190-94.

24. L.E. Van Belle, D.O. Carter and S.L. Forbes, Forensic Sci Int. 193 (2009) 3741.

25. R. Jelly, E.L.T. Patton, C. Lennard, S.W. Lewis and K.F. Lim, Anal Chim Acta. 652(1-2) (2009) 128-42.

26. D.O. Carter, D. Yellowlees and M. Tibbett, Naturwissenschaften. 94(1) (2007) 12-24.

27. M. Amato and J.N. Ladd, Soil Biol Biochem. 20(1) (1988) 107-14.

28. T.M. Lovestead and T.J. Bruno, Forensic Sci Int. DOI: 10.1016/j.forsciint.2010.05.024 (2010)

29. B.H. Stuart, L. Craft, S.L. Forbes and B.B. Dent, Forensic Sci Med Pathol. 1-3 (2005) 197-201.

30. B.H. Stuart, S. Forbes, B.B. Dent and G. Hodgson, Vibr Spectrosc. 24(2) (2000) 233-42.

31. S.J. Notter, B.H. Stuart, R. Rowe and N. Langlois, J Forensic Sci. 54(1) (2009) 195-201.

32. D.A. Skoog, F.J. Holler and S.R. Crouch, Principles of Instrumental Analysis, 6th ed., Brooks Cole, 2006.

33. F.A. Jaffe, J Forensic Sci. 7 (1962) 231-37.

34. W.Q. Sturner, Lancet. 1 (1963) 807-08.

35. F. Tagliaro, F. Bortolotti, G. Manetto, F. Cittadini, V.L. Pascali and M. Marigo, J Chromatogr A. 924(1-2) (2001) 493-98.

36. L. Swann, G.E. Chidlow, S. Forbes and S.W. Lewis, J Forensic Sci. 55(2) (2010) 308-14.

37. L. Swann, S. Forbes and S.W. Lewis, Aust J Forensic Sci. 42(3) (2010) 199210.

38. L.M. Swann, S.L. Forbes and S.W. Lewis, Talanta. 81(4-5) (2010) 1697-702.

39. H. Tuller. Dirty Secrets: Blood protein and VFA analysis of soil from execution and grave sites in the former Yugoslavia. Masters. Michigan State University; 1991.

40. W.J. Patrick and R.W. Logan, Arch Dis Child. 63 (1988) 660-62.

41. T.O. Rognum, S. Hauge, S. Oyasaeter and O.D. Saugstad, Forensic Sci Int. 51(1) (1991) 139-46.

42. B. Madea, H. Kaferstein, N. Hermann and G. Sticht, Forensic Sci Int. 65(1) (1994) 19-31. 
43. R.A. James, P.A. Hoadley and B.G. Sampson, Am J Forensic Med Pathol. 18(2) (1997) 158-62.

44. K.E. Ferslew, A.N. Hagardorn, M.T. Harrison and W.F. McCormick, Electrophoresis. 19(1) (1998) 6-10.

45. F. Tagliaro, G. Manetto, F. Cittadini, D. Marchetti, F. Bortolotti and M. Marigo, J Chromatogr B Analyt Technol Biomed Life Sci. 733(1-2) (1999) 273-79.

46. G. Bocaz-Beneventi, F. Tagliaro, F. Bortolotti, G. Manetto and J. Havel, Int J Legal Med. 116(1) (2002) 5-11.

47. J.I.M. Barus, J.M.S. Suarez-Penaranda, X.L. Otero, M.S. Rodriguez-Calvo, E. Costas, X. Miguens, and L. Concheiro, Forensic Sci Int. 125(1) (2002) 67-74.

48. S.L. Forbes, J. Keegan, B.H. Stuart and B.B. Dent, Eur J Lipid Sci Tech. 105(12) (2003) 761-68.

49. A.A. Vass, R.R. Smith, C.V. Thompson, M.N. Burnett, D.A. Wolf, J.A. Synstelien, N. Dulgerian, and B.A. Eckenrode, J Forensic Sci. 49(4) (2004) 760-69.

50. M. Statheropoulos, C. Spiliopouiou and A. Agapiou, Forensic Sci Int. 153(23) (2005) 147-55.

51. J.I. Munoz, E. Costas, M.S. Rodriguez-Calvo, J.M. Suarez-Penaranda, M. Lopez-Rivadulla and L. Concheiro, Hum Exp Toxicol. 25 (2006) 279-81.

52. B. Zhou, L. Zhang, G.Q. Zhang, X.S. Zhang and X.P. Jiang, J Chromatogr B Analyt Technol Biomed Life Sci. 852(1-2) (2007) 278-81.

53. M. Statheropoulos, A. Agapiou, C. Spiliopouiou, G.C. Pallis and E. Sianos, Sci Total Environ. 385(1-3) (2007) 221-27.

54. E. Girela, E. Villanueva, P. Irigoyen, V. Girela, C. Hernandez-Cueto and J.M. Peinado, J Forensic Sci. 53(3) (2008) 730-33.

55. S.J. Notter, B.H. Stuart, B.B. Dent and J. Keegan, Eur J Lipid Sci Tech. 110(1) (2008) 73-80.

56. J. Dekeirsschieter, F.J. Verheggen, M. Gohy, F. Hubrecht, L. Bourguignon, G. Lognay, and E. Haubruge, Forensic Sci Int. 189(1-3) (2009) 46-53.

57. L. Adelson, I. Sunshine, N.B. Rushforth and M. Manforth, J Forensic Sci. 8 (1963) 503-14.

58. J.I. Coe, Am J Clin Pathol. 51(6) (1969) 741-50.

59. J.B. Henry and F.A. Smith, Am J Forensic Med Pathol. 1(4) (1980) 341-47.

60. L. Hansson, U. Uotila, R. Lindfors and K. Laiho, J Forensic Sci. 2 (1966) 39094.

61. B. Madea, C. Henssge, W. Honig and A. Gerbracht, Forensic Sci Int. 40(3) (1989) 231-43.

62. B. Madea and A. Rodig, Forensic Sci Int. 164(2-3) (2006) 87-92.Doi 10.1016/J.Forsciint.2005.12.002.

63. B. Madea, Forensic Sci Int. 151(2-3) (2005) 139-49.

64. J.I. Coe, Forensic Sci Int. 42(3) (1989) 201-13.

65. B. Madea, N. Herrmann and C. Henbge, Forensic Sci Int. 46(3) (1990) 27784.

66. D.L. Sparks, P.R. Oeltgen, R.J. Kryscio and J.C. Hunsaker, J Forensic Sci. 34(1) (1989) 197-206.

67. M. Krizek and T. Pelikanova, J Chromatogr A. 815(2) (1998) 243-50.

68. N. Zhang, H. Wang, Z.-X. Zhang, Y.-H. Deng and H.-S. Zhang, Talanta. 76(4) (2008) 791-97. 
69. G. Nouadje, N. Simeon, F. Dedieu, M. Nertz, P. Puig and F. Couderc, J Chromatogr A. 765(2) (1997) 337-43.

70. R.A. Harkness, J Chromatogr Biomed Appl. 429 (1988) 255-78.

71. M.L.C. Passos, A.M. Santos, A.I. Pereira, J. Rodrigo Santos, A.J.C. Santos, M.L.M.F.S. Saraiva, and J.L.F.C. Lima, Talanta. 79 (2009) 1094-99.

72. C.E. Lenehan, N.W. Barnett and S.W. Lewis, Analyst. 127(8) (2002) 9971020 .

73. Z. Erdei and Z. Vass, Acta Ophthal. 45 (1967) 22-24.

74. E.M. Williams, D. Donaldson and D.M. Matthews, Clin Chim Acta. 12 (1965) 468-70.

75. I.R. Kennedy, Anal Biochem. 11 (1965) 105-10.

76. Y.P. Lee and T. Takahashi, Anal Biochem. 14 (1966) 71-77.

77. K. Schoenly, K. Griest and S. Rhine, J Forensic Sci. 36(5) (1991) 1395-415.

78. M.S. Archer and A.A. Elgar, Med Vet Entomol. 17(3) (2003) 263-71.

79. M.L. Goff, J Forensic Sci. 36(3) (1991) 748-53.

80. M.L. Goff and M.M. Flynn, J Forensic Sci. 36(2) (1991) 607-14.

81. M.S. Archer, Australian Journal of Zoology. 51(6) (2003) 569-76.Doi 10.1071/Zo03053.

82. M.S. Archer, J Forensic Sci. 49(3) (2004) 553-59.

83. L.M.L. Carvalho, A.X. Linhares and J.R. Trigo, Forensic Sci Int. 120(1-2) (2001) 140-44.

84. K.A. George, M.S. Archer, L.M. Green, X.A. Conlan and T. Toop, Forensic Sci Int. 193 (2009) 21-25.

85. B. Turner and P. Wiltshire, Forensic Sci Int. 101(2) (1999) 113-22.

86. K.G. Schoenly, N.H. Haskell, D.K. Mills, C. Bieme-Ndi, K. Larsen and Y. Lee, Am Biol Teach. 68(7) (2006) 402-10.

87. C.A. Hordijk, I. Burgers, G.J.M. Phylipsen and T.E. Cappenberg, J Chromatogr. 511 (1990) 317-23.

88. S. Willig, M. Lacorn and R. Claus, J Chromatogr A. 1038(1-2) (2004) 11-18.

89. A.E. Van Den Bogaard, M.J. Hazen and C.P. Van Boven, Clin Microbiol. 23(3) (1986) 523-30.

90. G. Manni and F. Caron, J Chromatogr A. 690(2) (1995) 237-42.

91. R.G. Ackman and R.D. Burgher, Anal Chem. 35(6) (1963) 647-52.

92. D.C. Harris, Quantitative Chemical Analysis, 4th ed., W.H. Freeman and Company, U.S.A., 1995.

93. D.A. Skoog, D.M. West, F.J. Holler and S.R. Crouch, Fundamentals of Analytical Chemistry, 8th ed., Brooks Cole, USA, 2004.

94. K. Robards, P.R. Haddad and P.E. Jackson, Principles and practice of modern chromatographic methods, Academic Press Ltd., London, U.K., 1994.

95. H.A. Barker, Annu Rev Biochem. 50 (1981) 23-40.

96. R.I. Mackie, P.G. Stroot and V.H. Varel, J Anim Sci. 76(5) (1998) 1331-42.

97. S.L. Forbes, B.H. Stuart and B.B. Dent, Forensic Sci Int. 127(3) (2002) 22530.

98. L. Verbiest. Characterisation of fluids produced during the decomposition of porcine flesh. Honours Thesis. Curtin University of Technology; 2006.

99. S. Oguri, J Chromatogr B Analyt Technol Biomed Life Sci. 747(1-2) (2000) $1-19$.

100. H.J. Isaaq, Electrophoresis. 20 (1999) 3190-202. 
101. R.L. Cunico, K.M. Gooding and T. Wehr, Basic HPLC and CE of Biomolecules, Bay Bioanalytical Laboratory, Inc., Richmond, California, 1998.

102. A.M. Curran, P.A. Prada and K.G. Furton, J Forensic Sci. 55(1) (2010) 50-57.

103. D.T. Hudson, A.M. Curran and K.G. Furton, J Forensic Sci. 54(6) (2009) 1270-77.

104. S.L. Forbes, B.H. Stuart, B.B. Dent and S. Fenwick-Mulcahy, J Forensic Sci. 50(3) (2005) 633-40.

105. T. Takatori and A. Yamaoka, Forensic Sci. 10(2) (1977) 117-25.

106. T. Takatori, Forensic Sci Int. 80(1-2) (1996) 49-61. 
Figure 1:<smiles>CCC(=O)O</smiles>

propionic acid<smiles>CCCC(=O)O</smiles>

butyric acid<smiles>CCCCC(=O)O</smiles>

valeric acid<smiles>CC(C)C(=O)O</smiles>

iso-butyric acid<smiles>CC(C)CC(=O)O</smiles>

iso-valeric acid

Figure 2:

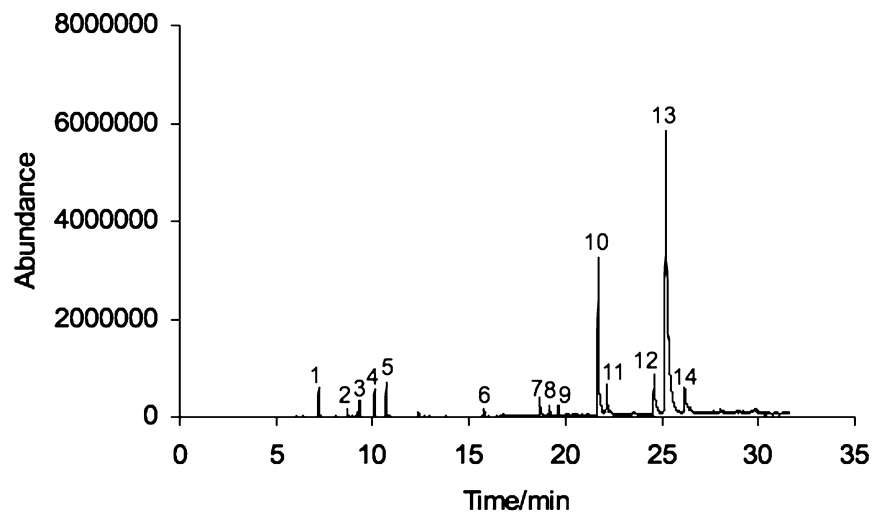

Figure 3:<smiles>NC(Cc1ccccc1)C(=O)O</smiles>

(III) 
Figure 4

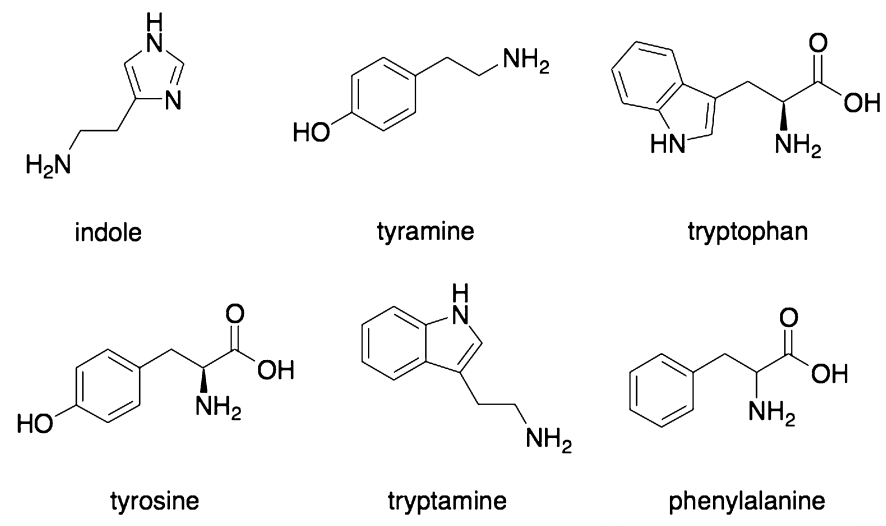

Figure 5:

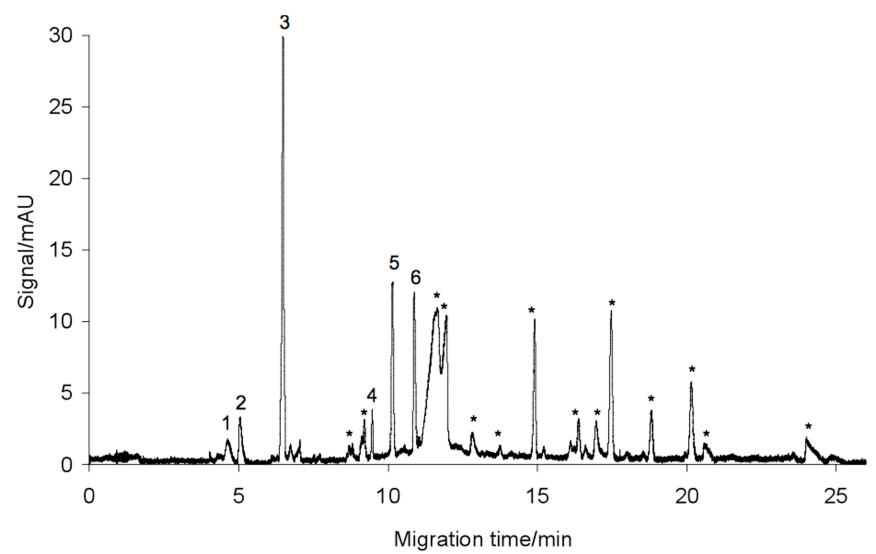

Figure 6:

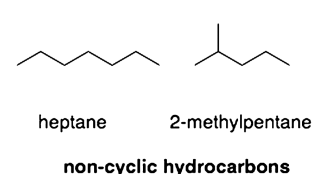

non-cyclic hydrocarbons

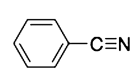

benzonitrile

nitrogen compounds

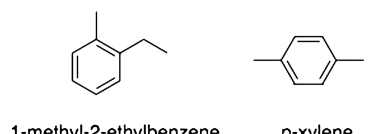

1-methyl-2-ethylbenzene $\quad p$-xylene cyclic hydrocarbons

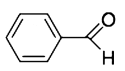

benzaldehyde

xygen compounds

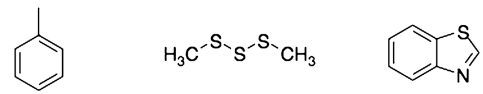

toluene

dimethyl trisulfide benzothiazole sulfur compounds

$$
\mathrm{F}{\underset{\mathrm{Cl}}{\mathrm{Cl}} \mathrm{F}}^{\mathrm{C}}
$$

dichlorodifluoromethane

1-chlorobutane $\mathrm{Cl} \stackrel{\mathrm{Cl}}{\mathrm{Cl}}_{\mathrm{Cl}}$

tetrachloromethane 
Figure 7:<smiles>CCCCCCCCCCCCCCC(=O)O</smiles>

palmitic acid<smiles>CCCCCCCCCCCCCCCCCC(=O)O</smiles>

stearic acid<smiles>CCCCCCCCCCCCCC(=O)O</smiles>

myristic acid<smiles>CCCCCC/C=C\CCCCCCCC(=O)O</smiles>

9-hexadecenoic acid

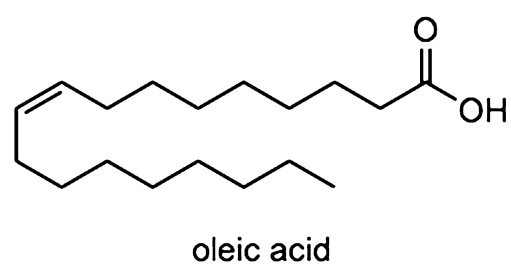<smiles>CCCCC/C=C\C/C=C\CCCCCCCC(=O)O</smiles>

linoleic acid 
Table 1 Overview of mammalian decomposition

\begin{tabular}{|c|c|c|}
\hline $\begin{array}{l}\text { STAGE OF } \\
\text { DECOMPOSITION }\end{array}$ & DESCRIPTION & REFERENCE \\
\hline FRESH & $\begin{array}{l}\text { Commences immediately after death } \\
\text { Autolysis } \\
\text { Fluid filled blisters on the skin, skin slippage } \\
\text { Marbling of skin due to livor mortis }\end{array}$ & $\begin{array}{l}{[14]} \\
{[6,7]} \\
{[6,7,12]}\end{array}$ \\
\hline BLOATING & $\begin{array}{l}\text { Putrefaction - destruction of soft tissues by } \\
\text { microorganisms } \\
\text { Greenish discolouration of the skin } \\
\text { Gas and fluid accumulation followed by purging } \\
\text { Anaerobic fermentation }\end{array}$ & $\begin{array}{l}{[7,11]} \\
{[6,7,12]} \\
{[12]}\end{array}$ \\
\hline ACTIVE DECAY & $\begin{array}{l}\text { Bloating has ceased } \\
\text { Skin usually broken in one or more places } \\
\text { Rapid leaching from body } \\
\text { Large numbers of aerobic and anaerobic bacteria } \\
\text { Extensive insect activity } \\
\text { Possible carnivore activity } \\
\text { Collapse of abdominal cavity } \\
\text { Loss of internal organs through insect activity or } \\
\text { autolysis } \\
\text { Possible adipocere formation }\end{array}$ & $\begin{array}{l}{[14]} \\
{[7]} \\
{[7,11,15]} \\
{[15]} \\
{[12,15]} \\
{[15]}\end{array}$ \\
\hline DRY & $\begin{array}{l}\text { Diagenesis } \\
\text { No carrion fauna remaining } \\
\text { Small amount of decaying tissue } \\
\text { Mummification of remaining skin } \\
\text { Bone exposure and skeletonisation }\end{array}$ & $\begin{array}{l}{[12,14]} \\
{[14]} \\
{[15]} \\
{[11,15]}\end{array}$ \\
\hline
\end{tabular}


Table 2. Summary of chromatographic methods used in the analysis of mammalian soft tissue decomposition products and to aid in the estimation of postmortem interval.

\begin{tabular}{|c|c|c|c|c|c|c|}
\hline Authors & $\begin{array}{l}\text { Analysis } \\
\text { method }\end{array}$ & Matrix & $\begin{array}{l}\text { Postmortem } \\
\text { interval of } \\
\text { samples }\end{array}$ & Analytes & $\begin{array}{l}\text { Analytical conditions/sample } \\
\text { preparation }\end{array}$ & Application \\
\hline $\begin{array}{l}\text { Rognum et al. } \\
1991[40]\end{array}$ & HPLC-UV & $\begin{array}{l}\text { Vitreous } \\
\text { humor }\end{array}$ & $<120 \mathrm{hrs}$ & $\begin{array}{l}\text { Hypoxanthine } \\
(\mathrm{Hx})\end{array}$ & $\begin{array}{l}\text { Mobile phase: } 0.005 \mathrm{M} \mathrm{KH}_{2} \mathrm{PO}_{4} \text {, } \\
\text { pH } 5.7 \\
\text { Column: Reverse phase, } 0.46 \mathrm{x} \\
15 \mathrm{~cm} \\
\text { Detection: } 254 \mathrm{~nm}\end{array}$ & $\begin{array}{l}\text { Estimation of } \\
\text { postmortem interval }\end{array}$ \\
\hline
\end{tabular}




\begin{tabular}{|c|c|c|c|c|c|c|}
\hline Authors & $\begin{array}{l}\text { Analysis } \\
\text { method }\end{array}$ & Matrix & $\begin{array}{l}\text { Postmortem } \\
\text { interval of } \\
\text { samples }\end{array}$ & Analytes & $\begin{array}{l}\text { Analytical conditions/sample } \\
\text { preparation }\end{array}$ & Application \\
\hline $\begin{array}{l}\text { James et al. } \\
1997[42]\end{array}$ & HPLC-UV & $\begin{array}{l}\text { Vitreous } \\
\text { humor }\end{array}$ & $\begin{array}{l}\text { Known but } \\
\text { not given }\end{array}$ & $\mathrm{Hx}$ & $\begin{array}{l}\text { Mobile phase: } 0.005 \mathrm{~m} \mathrm{KH}_{2} \mathrm{PO}_{4} \text {, } \\
\text { pH } 3.2 \\
\text { Column: Reverse phase } 18,0.45 \\
\text { x } 12.5 \mathrm{~cm} \\
\text { Detection: } 250 \mathrm{~nm}\end{array}$ & $\begin{array}{l}\text { Estimation of } \\
\text { postmortem interval, } \\
\text { comparison of } \\
\text { previously published } \\
\text { equations. }\end{array}$ \\
\hline
\end{tabular}




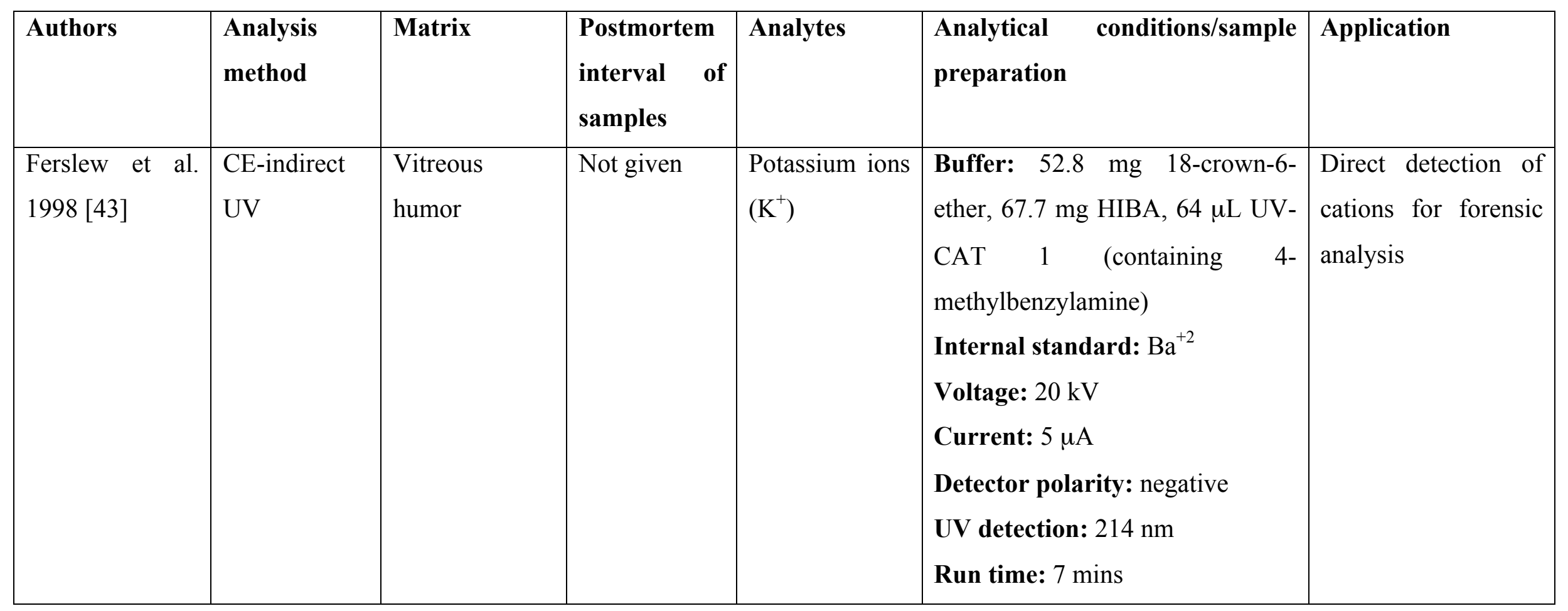




\begin{tabular}{|c|c|c|c|c|c|c|}
\hline Authors & $\begin{array}{l}\text { Analysis } \\
\text { method }\end{array}$ & Matrix & $\begin{array}{l}\text { Postmortem } \\
\text { interval of } \\
\text { samples }\end{array}$ & Analytes & $\begin{array}{l}\text { Analytical conditions/sample } \\
\text { preparation }\end{array}$ & Application \\
\hline
\end{tabular}




\begin{tabular}{|c|c|c|c|c|c|c|}
\hline Authors & $\begin{array}{l}\text { Analysis } \\
\text { method }\end{array}$ & Matrix & $\begin{array}{l}\text { Postmortem } \\
\text { interval of } \\
\text { samples }\end{array}$ & Analytes & $\begin{array}{l}\text { Analytical conditions/sample } \\
\text { preparation }\end{array}$ & Application \\
\hline
\end{tabular}




\begin{tabular}{|c|c|c|c|c|c|c|}
\hline Authors & $\begin{array}{l}\text { Analysis } \\
\text { method }\end{array}$ & Matrix & $\begin{array}{l}\text { Postmortem } \\
\text { interval of } \\
\text { samples }\end{array}$ & Analytes & $\begin{array}{l}\text { Analytical conditions/sample } \\
\text { preparation }\end{array}$ & Application \\
\hline
\end{tabular}




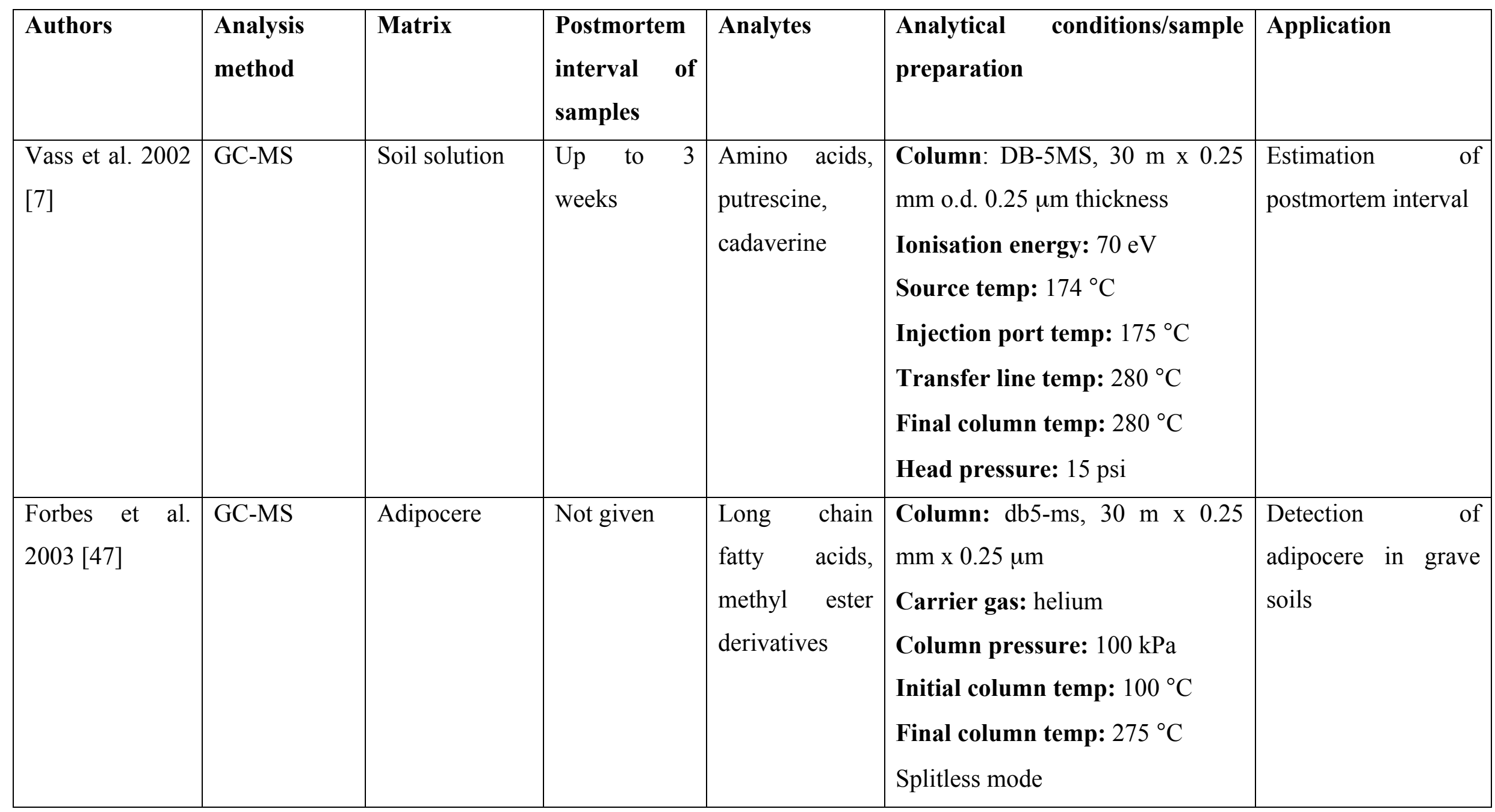




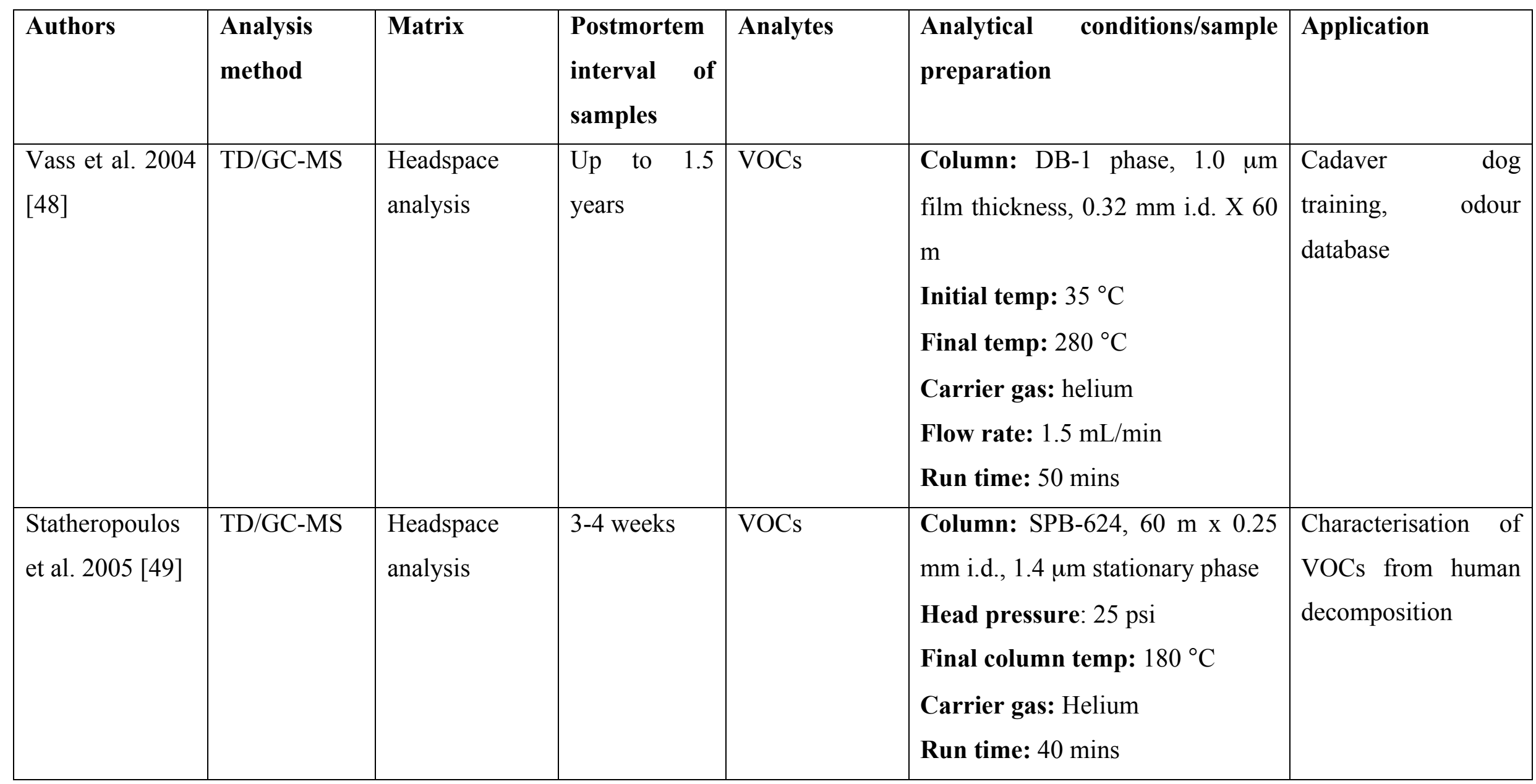




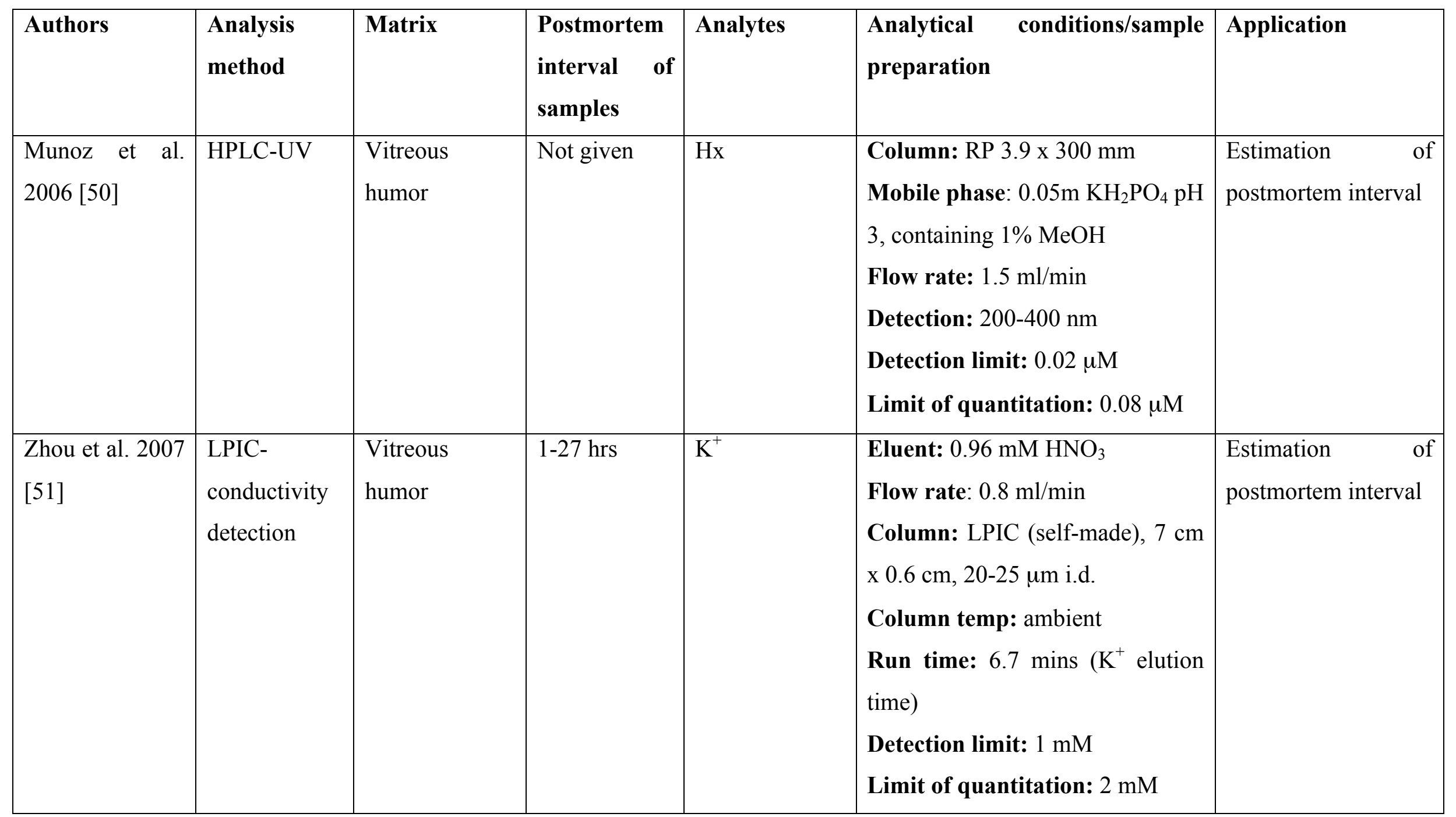




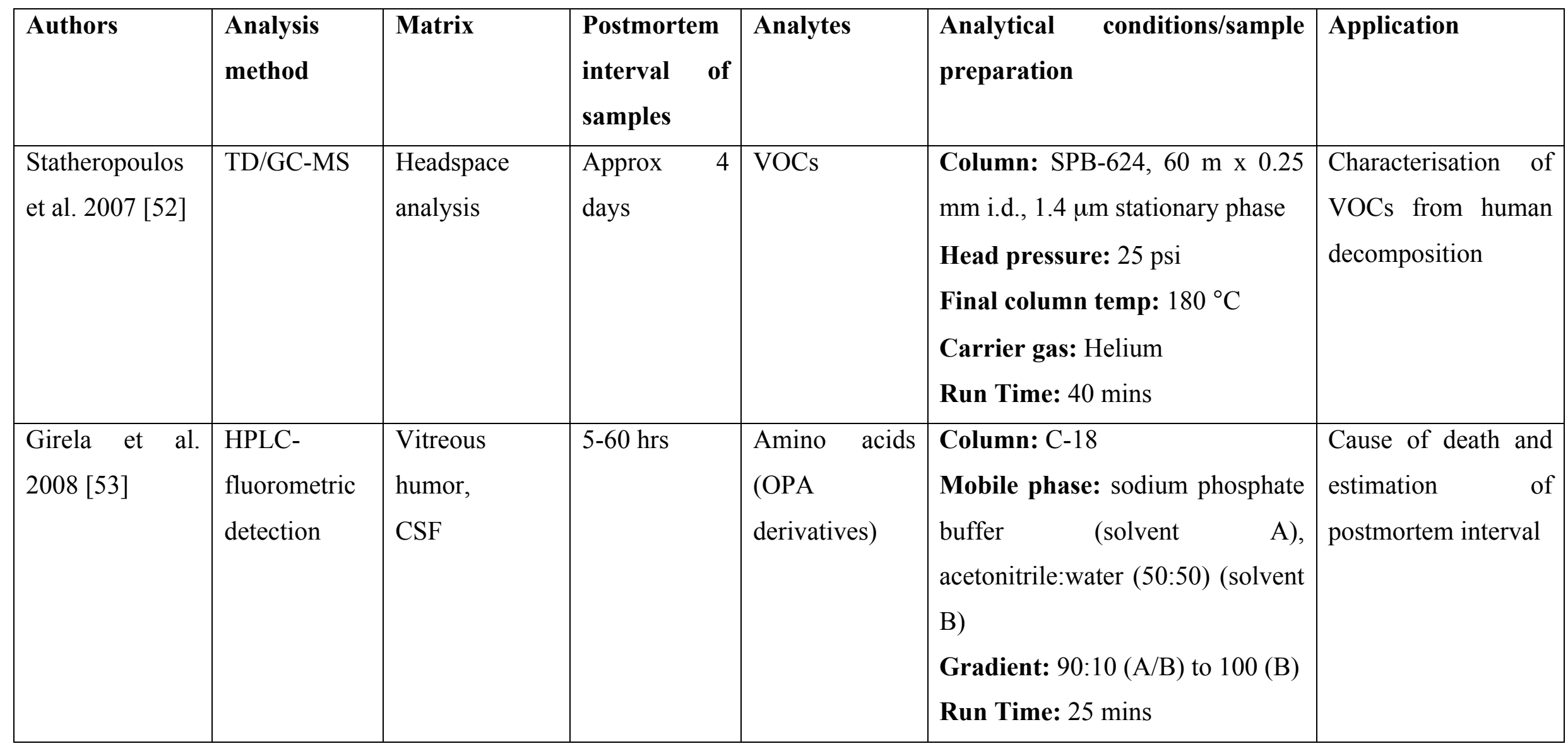




\begin{tabular}{|c|c|c|c|c|c|c|}
\hline Authors & $\begin{array}{l}\text { Analysis } \\
\text { method }\end{array}$ & Matrix & $\begin{array}{l}\text { Postmortem } \\
\text { interval of } \\
\text { samples }\end{array}$ & Analytes & $\begin{array}{l}\text { Analytical conditions/sample } \\
\text { preparation }\end{array}$ & Application \\
\hline
\end{tabular}




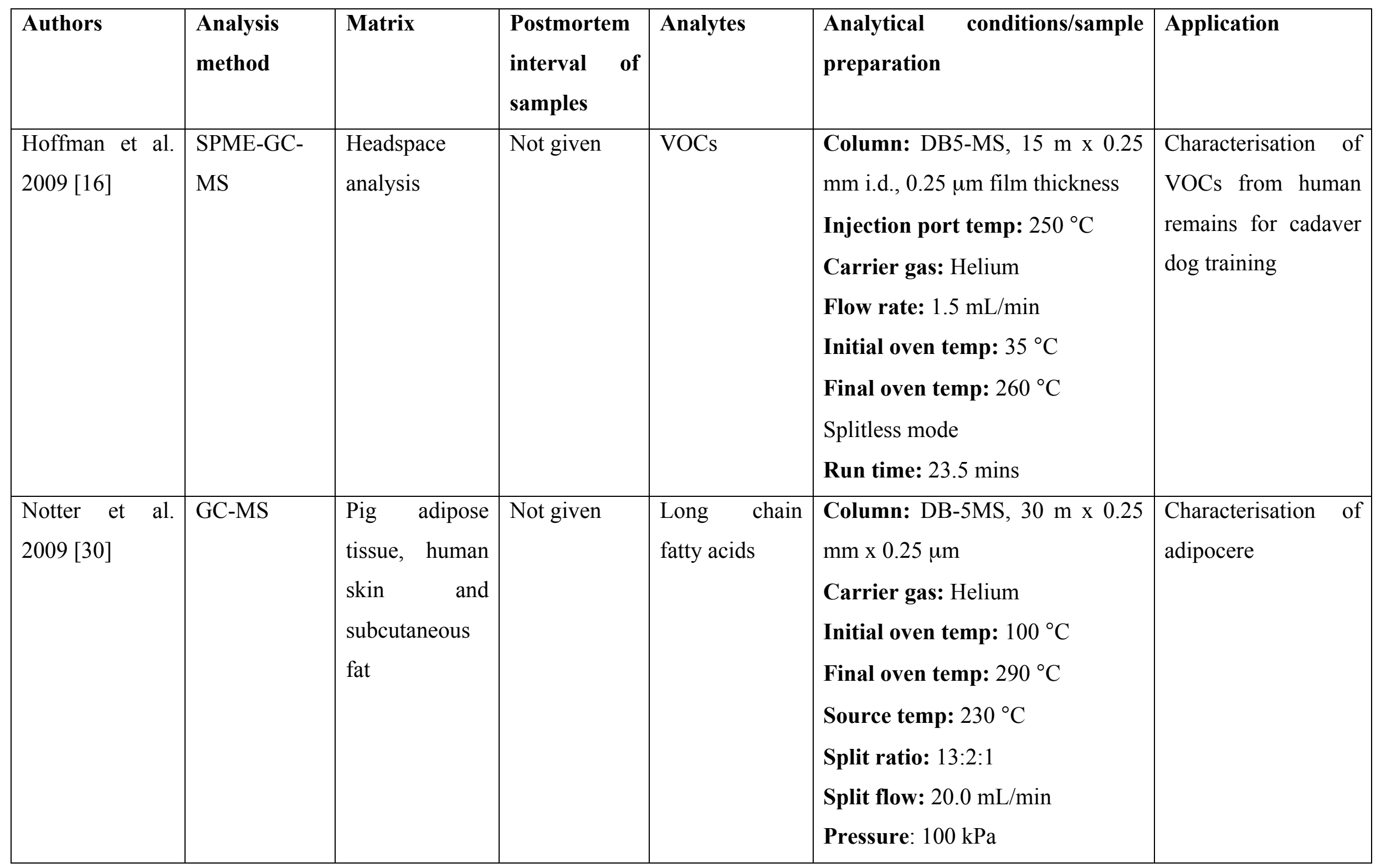




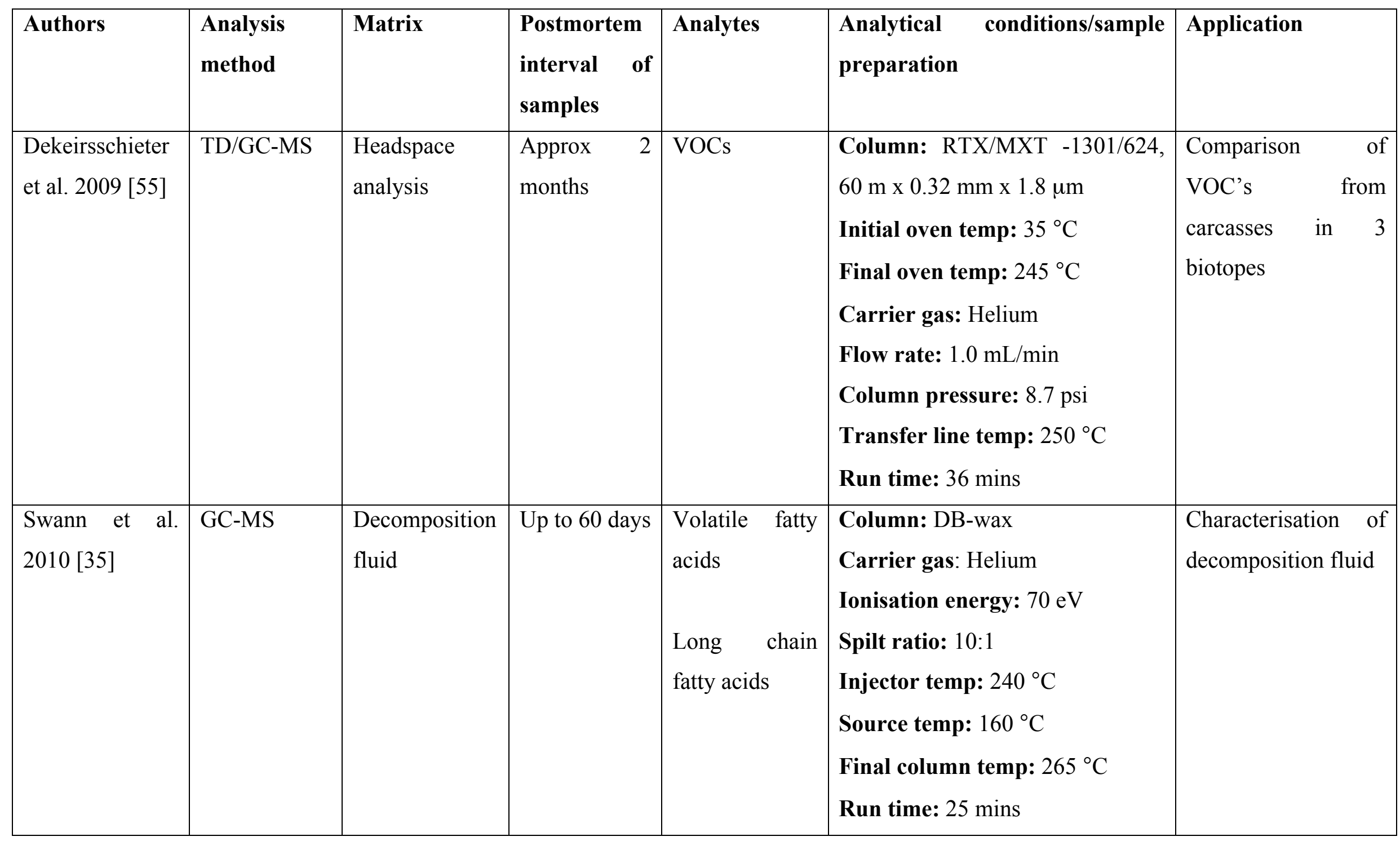




\begin{tabular}{|c|c|c|c|c|c|c|}
\hline Authors & $\begin{array}{l}\text { Analysis } \\
\text { method }\end{array}$ & Matrix & $\begin{array}{l}\text { Postmortem } \\
\text { interval of } \\
\text { samples }\end{array}$ & Analytes & $\begin{array}{l}\text { Analytical conditions/sample } \\
\text { preparation }\end{array}$ & Application \\
\hline
\end{tabular}

